\title{
Glutathione peroxidase 4 maintains a stemness phenotype, oxidative homeostasis and regulates biological processes in Panc-1 cancer stem-like cells
}

\author{
GUIQIN PENG ${ }^{1 *}$, ZONGWEI TANG $^{1 *}$, YONGJIA XIANG ${ }^{1}$ and WANYI CHEN ${ }^{2}$ \\ ${ }^{1}$ Key Laboratory for Biorheological Science and Technology of Ministry of Education (Chongqing University); \\ ${ }^{2}$ Chongqing Key Laboratory of Translational Research for Cancer Metastasis and Individualized Treatment, \\ Chongqing University Cancer Hospital and Chongqing Cancer Institute and Chongqing Cancer Hospital, \\ Chongqing 400030, P.R. China
}

Received June 13, 2018; Accepted November 8, 2018

DOI: $10.3892 /$ or.2018.6905

\begin{abstract}
Reactive oxygen species (ROS) have been widely accepted as critical molecules playing regulatory roles in various biological processes, including proliferation, differentiation and apoptotic/ferroptotic/necrotic cell death. Emerging evidence suggests that ROS may be involved in the induction of epithelial-to-mesenchymal transition (EMT), which has been reported to promote cancer stem-like cell (CSC) generation. Recent data indicate that altered accumulation of ROS is associated with CSC generation, EMT and hypoxia exposure, but the underlying mechanisms are poorly understood. In the present study, we derived CSCs from Panc-1 human pancreatic cancer cells and characterized them using serial replating assays and western blot analysis. Functional identification of viable cells was performed using the CCK-8 assay and colony formation assays. The expression of various antioxidant enzymes, including superoxide dismutase (SOD) and glutathione peroxidase (GPX), was measured by western blot analysis in Panc-1 CSCs. The role of GPX4 in regulating biological processes of Panc-1 CSCs was assessed by proliferation, sphere formation and invasion assays with or without oxidative stress. Manipulation of GPX4 expression by siRNA knockdown or an overexpression vector was performed to assess functions including proliferation, colony formation and invasion. EMT hallmark genes were detected after GPX4
\end{abstract}

Correspondence to: Professor Wanyi Chen, Chongqing Key Laboratory of Translational Research for Cancer Metastasis and Individualized Treatment, Chongqing University Cancer Hospital and Chongqing Cancer Institute and Chongqing Cancer Hospital, Chongqing 400030, P.R. China

E-mail: 32003371@qq.com

${ }^{*}$ Contributed equally

Key words: cancer stem-like cells, GPX4, epithelial-to-mesenchymal transition, reactive oxygen species, superoxide dismutase alteration by RT-qPCR and western blot analysis. Panc-1 CSCs displayed more resistance to hypoxia exposure. Compared with the parental Panc-1 cells, Panc-1 CSCs expressed an obviously higher endogenous GPX4 level, indicating their role in maintaining homeostasis. During GPX4 knockdown, ROS accumulation was promoted following oxidative stress exposure to either $\mathrm{H}_{2} \mathrm{O}_{2}$ or erastin. Additionally, overexpression of GPX4 eliminated ROS induction by oxidative stress exposure and thus, exerted protective effects on physiological processes in the Panc-1 CSCs. Knockdown of GPX4 arrested cell cycle progression at the $\mathrm{G}_{1} / \mathrm{G}_{0}$ phase; inhibited cell proliferation, colony formation, invasion and the stemness phenotype in the Panc-1 CSCs; and decreased the EMT phenotype. Collectively, GPX4 plays a critical role in maintaining oxidative homeostasis and regulates several biological processes, including stemness and EMT, in Panc-1 CSCs.

\section{Introduction}

Reactive oxygen species (ROS), which mainly encompass oxygen molecules containing one or more unpaired, unstable electrons, are important cellular signalling molecules involved in a variety of biological processes, including cell proliferation, differentiation and apoptosis (1). Both endogenous sources (such as mitochondria and peroxisomes) and exogenous sources (such as environmental agents, pharmaceuticals and irradiation) can induce ROS accumulation (2). ROS homeostasis is critical for maintaining normal physiological and biological processes. Accumulation of excess ROS, which is termed oxidative stress, can lead to irreversible injury to cells via damaged biomolecules, including DNA, resulting in genomic instability and genetic mutations that contribute to diseases such as tumourigenesis. In this case, the mechanisms for maintaining the low levels of intracellular ROS in mammalian cells are extremely important. The powerful scavenger antioxidant enzyme systems, including superoxide dismutase (SOD), catalase and glutathione peroxidase (GPX), have been well studied. Once formed, ROS are rapidly converted by SODs to $\mathrm{H}_{2} \mathrm{O}_{2}$. Newly formed $\mathrm{H}_{2} \mathrm{O}_{2}$ is converted to $\mathrm{H}_{2} \mathrm{O}+\mathrm{O}_{2}$ by GPX through coupling with reduced glutathione (GSH) and 
its subsequent conversion to oxidized glutathione (3). It has been reported that changes in GPX levels, especially in 5 of the 8 sub-members of the GPX family, are tightly associated with malignant phenotypes in several types of tumours (4). GPX1, GPX3 and GPX4 are reported to function as tumour suppressors in breast (5), colorectal (6), endometrial (7), pancreatic (8) and prostate (9) cancer. However, the regulatory roles that GPX family members play in tumours are still largely unknown.

Recently, the existence of cancer stem-like cells (CSCs) has been recognized (10). As a small proportion of cancer cells, CSCs exert potential roles in aggressive tumour phenotypes and malignant behaviours, such as chemoresistance, recurrence, relapse and metastasis. It is well established that, in stem cells, several signalling molecules are involved in and play critical roles in maintaining low levels of ROS, which may facilitate chemo/radiotherapy resistance and increased self-renewal capacity in stem cells (11-15). In cancer cells, accumulated intracellular ROS may function as a tumour suppressor or enhancer depending on the cellular mechanisms activated $(3,15)$. In comparison with normal stem cells or a heterogeneous population of cancer cells, the regulatory role of intracellular ROS in CSCs is still largely unknown. It has been reported that CSCs have lower intracellular ROS contents compared with a heterogeneous population of cancer cells (16), which may be due to upregulated expression of members of the free radical scavenging system, including the SODs or GPXs (17). Kim and colleagues showed that increased CD13, a CSC molecule, negatively regulates ROS, resulting in increased stemness in liver CSCs (18). This suggests an association between low levels of ROS with CSC stemness. However, the underlying mechanism for decreased ROS is not well understood in CSCs.

The EMT programme has been recognized as a major mechanism of tumour metastasis for 2 decades (19). Inactivation of E-cadherin, activation of vimentin, Slug and Snail are considered hallmarks of EMT programme activation (19). Surprisingly, it was observed that experimental activation of EMT, via either the overexpression of Twist1 or treatment with TGF $\beta$, confers many of the characteristics of CSCs on non-CSC epithelial carcinoma cells $(20,21)$. The association between EMT and CSCs indicates that EMT programme activation in non-CSC cells may enable their conversion into CSCs. In this case, both self-renewal capacity and an EMT phenotype are considered as CSC characteristics (22). However, little is known about whether inactivation of the EMT programme or activation of the MET programme affects biological processes in CSCs.

The established relationship between ROS and EMT $(23,24)$, and the regulatory mechanisms between EMT and CSCs (25) suggests that maintenance of oxidative homeostasis regulates the EMT process and the stemness phenotype via balancing ROS in CSCs. Differential expression of endogenous oxidative stress scavengers may play a critical role in leading to the imbalance or rebalance of oxidative stress and the ultimate effect on biological processes.

In the present study, we demonstrated the regulatory role of GPX4 in maintaining oxidative homeostasis and thus affecting the EMT programme and stemness phenotype of Panc-1 CSCs. We describe a novel role of GPX4 in regulating biological processes in Panc-1 CSCs, which indicates a promising further in CSCs induced metastasis.

\section{Materials and methods}

Cell cultures. The human pancreatic cancer cell line, Panc-1, was obtained from the American Type Culture Collection (ATCC; Manassas, VA, USA) and frozen in our laboratory in liquid nitrogen and cultured in Dulbecco's modified Eagle's medium (DMEM; Life Technologies; Thermo Fisher Scientific, Inc., Waltham, MA, USA) supplemented with $10 \%$ fetal bovine serum(FBS; Gibco; Thermo Fisher Scientific,Inc.,Paisley,UK), $100 \mathrm{U} / \mathrm{ml}$ of penicillin (Gibco; Thermo Fisher Scientific, Inc.), $100 \mu \mathrm{g} / \mathrm{ml}$ of streptomycin (Gibco; Thermo Fisher Scientific, Inc.) in a $5 \% \mathrm{CO}_{2}$ incubator at $37^{\circ} \mathrm{C}$. For enriching CSCs from parental Panc-1 cells, a suspension culture supporting proliferation of undifferentiated cells was adopted (26). Briefly, Panc-1 cells were maintained in DMEM/Ham's Nutrient Mixture F-12 (F-12) (1:1) (Life Technologies; Thermo Fisher Scientific, Inc.) with the addition of epidermal growth factor (EGF, 20 ng/ml; Sigma-Aldrich; Merck KGaA, Darmstadt, Germany), human fibroblast growth factor basic (hFGFb, $10 \mathrm{ng} / \mathrm{ml}$; Sigma-Aldrich; Merck KGaA) and 2\% B27 (Life Technologies; Thermo Fisher Scientific, Inc.) for 14-21 days. Medium was half-refreshed every 3 days until the spheres were observed.

Cell viability and apoptosis assays. Cell viability was determined by the Cell Counting Kit-8 (CCK-8; Dojindo Laboratories Co., Ltd., Kumamoto, Japan) assay. Briefly, Panc-1 or Panc-1 cancer stem-like cells (Panc-1 CSCs) $\left(5 \times 10^{4}\right)$ were cultured in 96-well plates. A total of $10 \mu \mathrm{l}$ of freshly prepared CCK-8 solution was added to the cell culture for a 2 -h co-incubation. The absorbance was measured at $620 \mathrm{~nm}$. The cell viability was expressed as OD (OD620).

The apoptosis of Panc-1 or Panc-1 CSCs was determined by FACS analysis of Annexin V-FITC/propidium iodide (PI; Roche, Basel, Switzerland)-double stained cells. Briefly, cells were grown in a 6-well plate in serum-free medium. After treatment, Panc-1 and Panc-1 CSCs were trypsinized, washed with phosphate-buffered saline (PBS), resuspended in $200 \mu \mathrm{l}$ PBS with $10 \mu \mathrm{l}$ RNAase $(10 \mathrm{mg} / \mathrm{ml})$ and incubated at $37^{\circ} \mathrm{C}$ for $30 \mathrm{~min}$. At the end of incubation, $50 \mu \mathrm{l}$ of Annexin V-FITC/PI labeling solution (BD Biosciences, San Jose, CA, USA) was added and cells were analyzed for apoptosis using a flow cytometry (BD FACSCanto II; BD Biosciences).

Hypoxia exposure. For hypoxia induction, cells were cultured under a hypoxic condition $\left(1 \% \mathrm{O}_{2}, 5 \% \mathrm{CO}_{2}\right.$ and $\left.94 \% \mathrm{~N}_{2}\right)$ in a multigas incubator (MCO-19; Sanyo Scientific, Tokyo, Japan) for 6,12 or $24 \mathrm{~h}$. For normoxia incubation, cells were incubated under the condition of $20 \% \mathrm{O}_{2}, 5 \% \mathrm{CO}_{2}$ and $75 \% \mathrm{~N}_{2}$.

Serial replating assay. For detecting self-renewal capacity of Panc-1 CSCs, CSCs were grown in 6-well ultra-low attachment plates (Corning Inc., Corning, NY, USA) at a density of 1,000 cells $/ \mathrm{ml}$ in well-defined serum-free medium at $37^{\circ} \mathrm{C}$ in a humidified atmosphere of $95 \%$ air and $5 \% \mathrm{CO}_{2}$. Fourteen days later, the spheres with a diameter of $>40 \mu \mathrm{m}$ were counted 
under an Olympus X71 (U-RFL-T) fluorescence microscope (Olympus Corp., Melville, NY, USA). Then, similarly, for secondary spheroids, the same number of CSCs from spheroids were reseeded for another 14 days. All the procedures were repeated 4 times.

siRNA transfection. Knockdown of the mRNA level of GPX4 was achieved by transient transfection of cells with siRNA duplexes (Thermo Fisher Scientific, Inc., Waltham, MA, USA), specific to the mRNA of GPX4. The relevant siRNA sequences were: GPX4 sense, 5'-UUCGAUAUGUUCAGC AAGAUU-3' and antisense, 5'-UCUUGCUGAACAUAU CGAAUU-3'; negative control (NC) sense, 5'-GUUCAAUAU UAUCAAGCGGUU-3' and antisense, 5'-CCGCUUGAUAAU AUUGAACUU-3'. According to the manufacturer's instructions, $5 \times 10^{5}$ cells were grown in $2 \mathrm{ml}$ of serum-free medium. A siRNA/transfection reagent complex was formed at room temperature by combining siRNA oligomer $(50 \mathrm{nM})$ with $5 \mu \mathrm{l}(2 \mu \mathrm{g} / \mathrm{ml})$ Lipofectamine $^{\mathrm{TM}} 2000$ transfection reagent (Thermo Fisher Scientific, Inc.) in $0.5 \mathrm{ml}$ Opti-MEM medium (Thermo Fisher Scientific, Inc.) and this was applied to cells for $48 \mathrm{~h}$ until they were harvested. Cells transfected with NC siRNA were considered as the control cells. For erastin treatment, $48 \mathrm{~h}$ after transfection, the cells were cultured in media supplemented with $2 \mu \mathrm{M}$ erastin or an equal amount of dimethyl sulfoxide (DMSO) (mock group) for 2, 4, 6 and $8 \mathrm{~h}$, respectively. After 3 washes with PBS, the cells were harvested for further analysis.

For $\mathrm{H}_{2} \mathrm{O}_{2}$ treatment, $48 \mathrm{~h}$ after transfection, cells were cultured in media supplemented with 50, 100, 200 and $500 \mu \mathrm{M}$ $\mathrm{H}_{2} \mathrm{O}_{2}$, respectively, for $24 \mathrm{~h}$. After 3 washes with PBS, cells were harvested for further analysis.

Construction of the expression plasmid and transfection. The full-length complementary DNA (cDNA) of GPX4 (human GPX4 GenBank accession no. NC_000019) was obtained from RiboBio Co., Ltd. (Guangzhou, China) and ligated into the NheI-XhoI site of the pcDNA3.1 vector (Life Technologies; Thermo Fisher Scientific, Inc.). The NheI and XhoI restriction enzymes and T4 ligase were purchased from Takara Bio (Heidelberg, Germany). A total of $0.8 \mu \mathrm{g}$ of the plasmid or empty vector was mixed with $4 \mu 1$ Lipofectamine ${ }^{\mathrm{TM}} 2000$ transfection reagent (Thermo Fisher Scientific, Inc.) in $0.5 \mathrm{ml}$ Opti-MEM medium (Thermo Fisher Scientific, Inc.) and this was applied to cells for $4 \mathrm{~h}$ followed by medium-refresh. After $24 \mathrm{~h}$, the culture medium was refreshed containing $500 \mu \mathrm{g} / \mathrm{ml}$ geneticin sulfate 418 (G418; Sigma-Aldrich; Merck KGaA) for antibiotic selection. Two weeks later, survival-transfected cells were collected and maintained in $250 \mu \mathrm{g} / \mathrm{ml} \mathrm{G} 418$.

For the apoptosis assay, cells were pretreated with $20 \mu \mathrm{M}$ caspase inhibitor Z-VAD-FMK (Promega Corporation, Madison, WI,USA), $1 \mu \mathrm{M}$ Ferrostatin-1 (Ferr-1; Sigma-Aldrich; Merck KGaA), or 0.3 $\mu \mathrm{M}$ Necrostatin-1 (Nec-1; Sigma-Aldrich; Merck KGaA) for $12 \mathrm{~h}$ followed by co-incubation of $\mathrm{H}_{2} \mathrm{O}_{2}$ or erastin, respectively. Twenty-four hours later, the cells were washed 3 times with PBS and harvested for further analysis.

$R T-q P C R$. The mRNA expression of GPX4, E-cadherin, vimentin, Slug, Snail and the housekeeping gene $\beta$-actin was determined by RT-qPCR using primer oligomers as followed:
GPX sense primer, 5'-CGATACGCTGAGTGTGGTTTGC-3' and antisense primer, 5'-CATTTCCCAGGATGCCCTTG-3'; E-cadherin sense primer, 5'-CGAGAGCTACACGTTCAC GG-3' and antisense primer, 5'-GGGTGTCGAGGGAAA AATAGG-3'; vimentin sense primer, 5'-GACGCCATCAAC ACCGAGTT-3' and antisense primer, 5'-CTTTGTCGTTGG TTAGCTGGT-3'; Slug sense primer, 5'-CGAACTGGACAC ACATACAGTG-3' and antisense primer, 5'-CTGAGGATC TCTGGTTGTGGT-3'; Snail sense primer, 5'-TCGGAAGCC TAACTACAGCGA-3' and antisense primer, 5'-AGATGA GCATTGGCAGCGAG-3'; $\beta$-actin sense primer, 5'-CATGTA CGTTGCTATCCAGGC-3' and antisense primer, 5'-CTCCTT AATGTCACGCACGAT-3'. Reverse transcription was carried out amplifying $1 \mu \mathrm{g}$ total RNA using a reverse transcriptase kit (Guangzhou Ribobio Co., Ltd.) according to the manufacturer's instructions. PCR was then carried out using PowerUp $\mathrm{SYBR}^{\mathrm{TM}}$-Green Master Mix (Thermo Fisher Scientific, Inc.) following the manufacturer's instructions. Briefly, the PCR conditions were started by denaturation for $5 \mathrm{~min}$ at $95^{\circ} \mathrm{C}$ and followed by 35 cycles of $95^{\circ} \mathrm{C}$ for $10 \mathrm{sec}$ and $60^{\circ} \mathrm{C}$ for $1 \mathrm{~min}$. mRNA levels were normalized against $\beta$-actin mRNA and for relative quantification, $2^{-\Delta \Delta \mathrm{Cq}}$ method was used (27).

ROS measurement. Total cellular ROS levels were determined using the Image-iT ${ }^{\mathrm{TM}}$ LIVE Green Reactive Oxygen Species (ROS) Detection kit (Invitrogen; Thermo Fisher Scientific, Inc.) according to the manufacturer's instructions. A total of $1 \times 10^{5}$ cells were used for analysis. Cells were washed with ice-cold 1X PBS and incubated with $50 \mu \mathrm{l}$ staining solution containing $25 \mu \mathrm{M}$ 5-(and-6)-carboxy-2',7'-dichlorodihydrofluorescein diacetate (carboxy- $\mathrm{H}_{2}$ DCFDA) for $30 \mathrm{~min}$ in darkness. Cells were washed twice with ice-cold $1 \mathrm{X}$ PBS and ROS levels were measured at 495/529 nm (for carboxy- $\mathrm{H}_{2}$ DCFDA) wavelengths on a Multiskan spectrum microplate reader (Thermo Fisher Scientific, Inc.).

Western blotting. Panc-1 or Panc-1 CSCs were washed twice with ice-cold 1X PBS, and then resuspended in lysis buffer containing $25 \mathrm{mM}$ HEPES buffer ( $\mathrm{pH} 7.6$ ), $3 \mathrm{mM} \mathrm{MgCl}{ }_{2}$, $40 \mathrm{mM} \mathrm{KCl}, 2 \mathrm{mM}$ DTT, 5\% glycerol and 0.5\% NP-40, and $1 \mathrm{X}$ protease inhibitor, and were maintained in an ice bath for $30 \mathrm{~min}$. After a 15 -min centrifugation at $12,000 \mathrm{x} \mathrm{g}$, at $4^{\circ} \mathrm{C}$, the supernatant was collected as total lysate. The protein concentration was determined using the Bradford protein assay procedure (Sigma-Aldrich; Thermo Fisher Scientific, Inc.). Twenty micrograms of protein was subjected to $10 \%$ SDS-PAGE, transferred to a polyvinylidene fluoride (PVDF) membrane (Thermo Fisher Scientific, Inc.), and incubated at room temperature overnight in PBS containing 5\% dried milk, 0.05\% Tween-20 and primary antibodies: Anti-superoxide dismutase 1 antibody (cat. no. ab13498; diluted at 1:2,000), anti-superoxide dismutase 2/MnSOD antibody (diluted at 1:2,000), anti-glutathione peroxidase 1 antibody (cat. no. ab22604; diluted at 1:1,000), anti-glutathione peroxidase 4 antibody (cat. no. ab125066; diluted at 1:2,000) (all from Abcam, Cambridge, MA, USA); anti-Nanog XP ${ }^{\circledR}$ rabbit monoclonal antibody (mAb) (cat. no. D73G4; diluted at 1:2,500), anti-c-Myc rabbit mAb (cat. no. D3N8F; diluted at 1:1,000), anti-Oct-4 antibody (cat. no. 2750; diluted at 1:1,000), anti-Sox2 antibody (cat. no. 3579; diluted at 1:2,000), anti-E-cadherin 
A

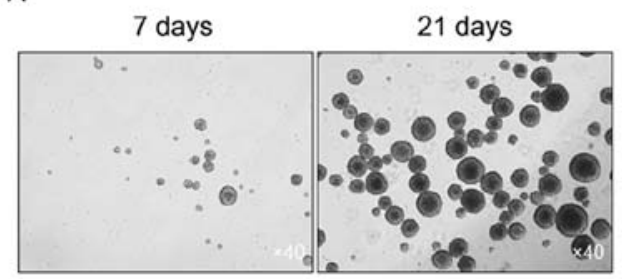

B

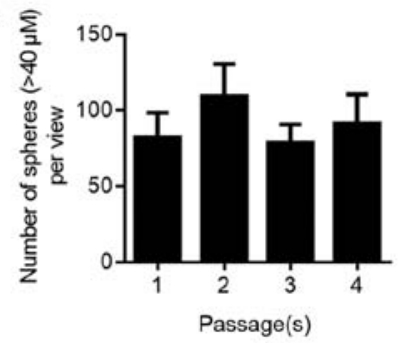

E

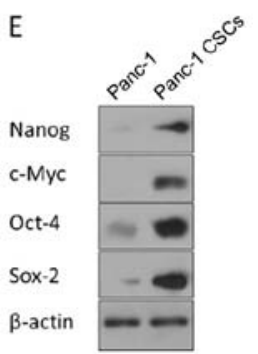

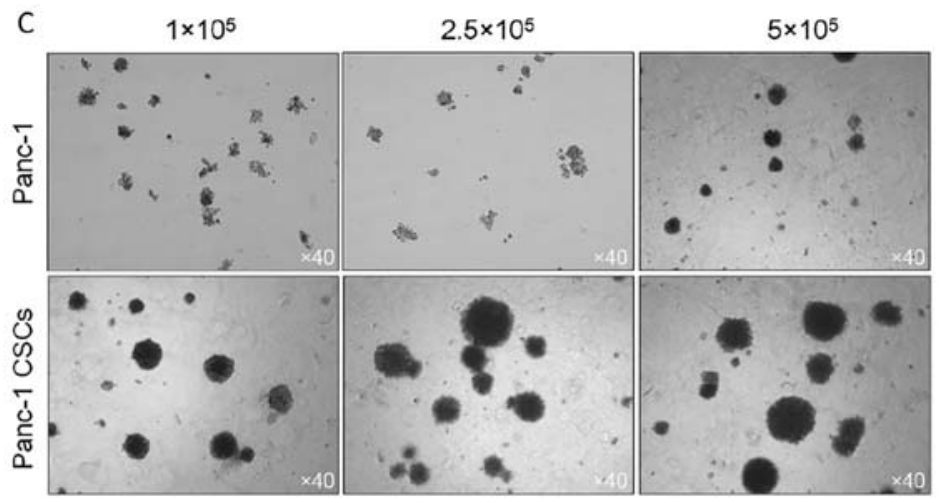

D

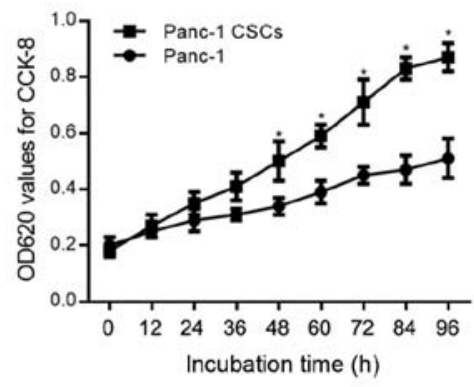

Figure 1. Enrichment and identification of CSCs from Panc-1 cells. (A) Morphology of CSCs enriched from Panc-1 cells at days 7 and 21. (B) Number of spheres in each view after self-replating assay. (C) Soft agar assay was performed to detect the tumor formation ability of Panc-1 and CSCs in vitro, respectively. (D) CCK-8 assay for detecting the proliferation of Panc-1 and Panc-1 CSCs. (E) Hallmarks of stemness were detected by western blot analysis. ${ }^{*} \mathrm{P}<0.05$ vs. Panc-1 cells. CSCs, cancer stem-like cells.

rabbit $\mathrm{mAb}$ (cat. no. 24E10; diluted at 1:2,000), anti-vimentin $\mathrm{XP}^{\circledR}$ rabbit mAb (cat. no. D21H3; diluted at 1:1,000), anti-Slug rabbit $\mathrm{mAb}$ (cat. no. C19G7; diluted at 1:1,000), anti-Snail rabbit $\mathrm{mAb}$ (cat. no. C15D3; diluted at 1:2,000), anti- $\beta$-actin mouse mAb (cat. no. 8H10D10; diluted at 1:5,000) (all from Cell Signaling Technology, Inc., Danvers, MA, USA). After 4 washes in PBS containing $0.05 \%$ Tween-20, the membrane was incubated with secondary antibody [anti-mouse $\mathrm{IgG}$, HRP-linked antibody (cat. no. 7076; diluted at 1:5,000), anti-rabbit IgG, HRP-linked antibody (cat. no. 7074; diluted at 1:5,000) (both from Cell Signaling Technology, Inc,)] for $1 \mathrm{~h}$, washed 4 times and the bound antibody was detected by chemiluminescence, and analyzed with ImageJ software (National Institutes of Health, Bethesda, MD, USA).

Statistical analysis. All the data are expressed as means \pm SD of 3 independent experiments. Unpaired Student's t-tests were used to compare the means of 2 groups. Differences between groups were analyzed by performing the ANOVA Kruskal-Wallis test, with Dunn's multiple group comparison test. P-values $<0.05$ were considered to indicate a statistically significant result.

\section{Results}

Characterization of CSCs derived from Panc-1 cells. After enriched Panc-1 CSCs were cultured for 7 and 21 days, it was obvious that the morphology of the pancreatic CSCs displayed sphere-like appearance (Fig. 1A). The ability of self-renew is the definition of a stem cell that is thought to be functionally mimicked by CSCs (28-30) and serial-replating assay which is widely employed (31), was performed to assess self-renewal of derived cells. As shown in Fig. 1B, no obvious difference in sphere formation ability was found between the cells at the 1st to 4 th passage. We then determined whether the spheroid cells have the capacity of high colony formation using Soft agar colony formation assay. Sphere-forming assay was performed to evaluate the stemness property of the Panc-1 cells. The results indicated that the stemness property of the Panc-1 cells was higher than that of their parental counterpart after a period of adaptation to $10 \%$ FBS containing medium, instead of serum-free medium (Fig. 1C). And as expected, the capacity of cell proliferation in the spheroid cells was significantly higher than that of their parental counterpart (Fig. 1D). Furthermore, 4 transcription factors which regulate the self-renewal capacity of CSCs (32) were detected by western blot analysis and the results showed that spheroid cells derived from Panc-1 cells displayed obviously higher expression levels of these 4 factors, compared to these levels in the parental counterpart (Fig. 1E).

Panc-1 CSCs display more resistant to hypoxic exposure and show induced expression levels of SOD1, SOD2, GPX1 and GPX4. Hypoxia has been reported to be a promoter of maintaining the stem-like phenotype of CSCs (33). To confirm whether CSCs derived from Panc-1 cells are resistant to hypoxic exposure, Panc-1 or Panc-1 CSCs were exposed to hypoxia for 6, 12 or $24 \mathrm{~h}$ and stained using Annexin V-FITC/PI double staining. As shown in Fig. 2A, in normoxia condition, no detectable difference between Panc-1 and Panc-1 CSCs in apoptotic cell death rate (Annexin V-FITC-positive/PI-negative and Annexin V-FITC-positive/PI-positive subpopulation) was noted. After being exposed to hypoxia for 12 and $24 \mathrm{~h}$, the apoptotic cell death rate in the Panc-1 CSCs $(4.3 \pm 0.5 \%$ for $12 \mathrm{~h} ; 0.8 \pm 0.6 \%$ for $24 \mathrm{~h}$ ) was obviously lower than that of the 
A
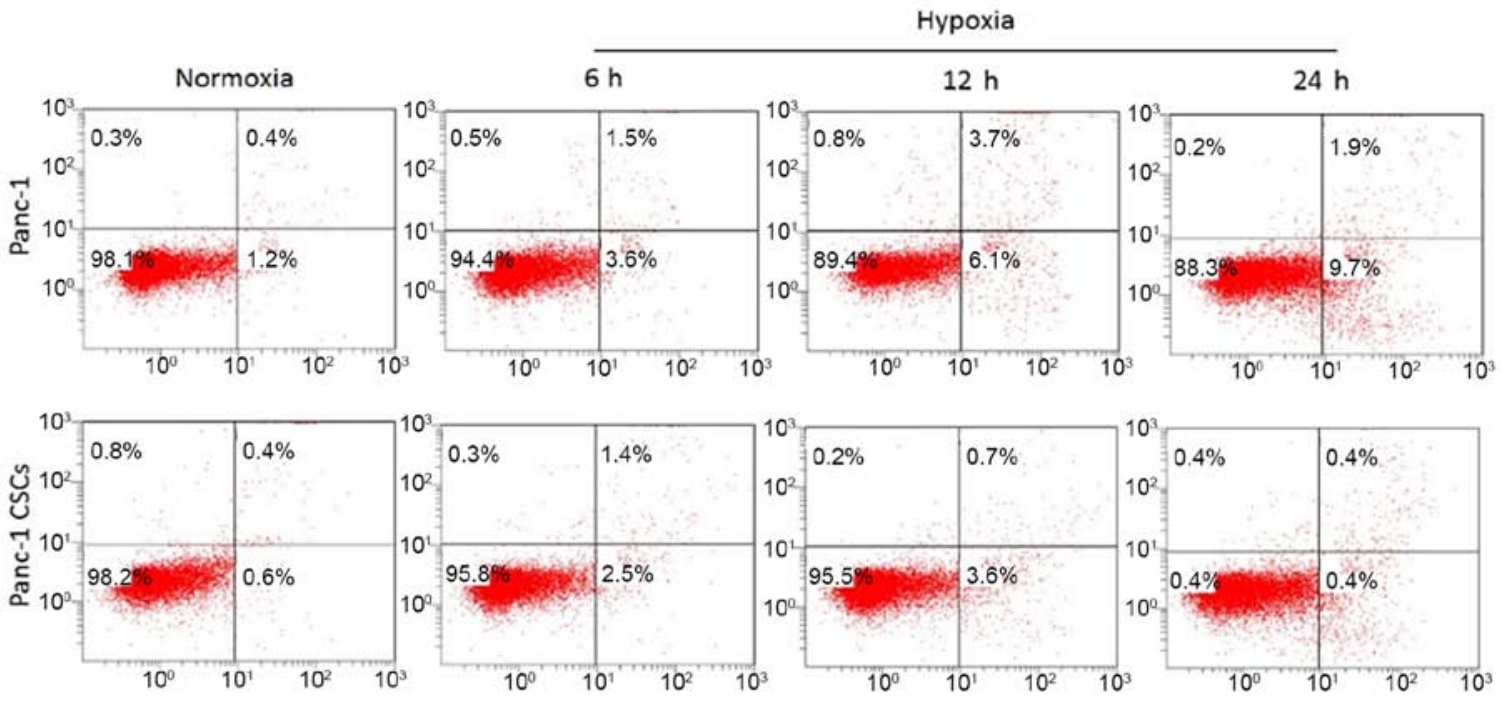

Annexin V-FITC staining

B
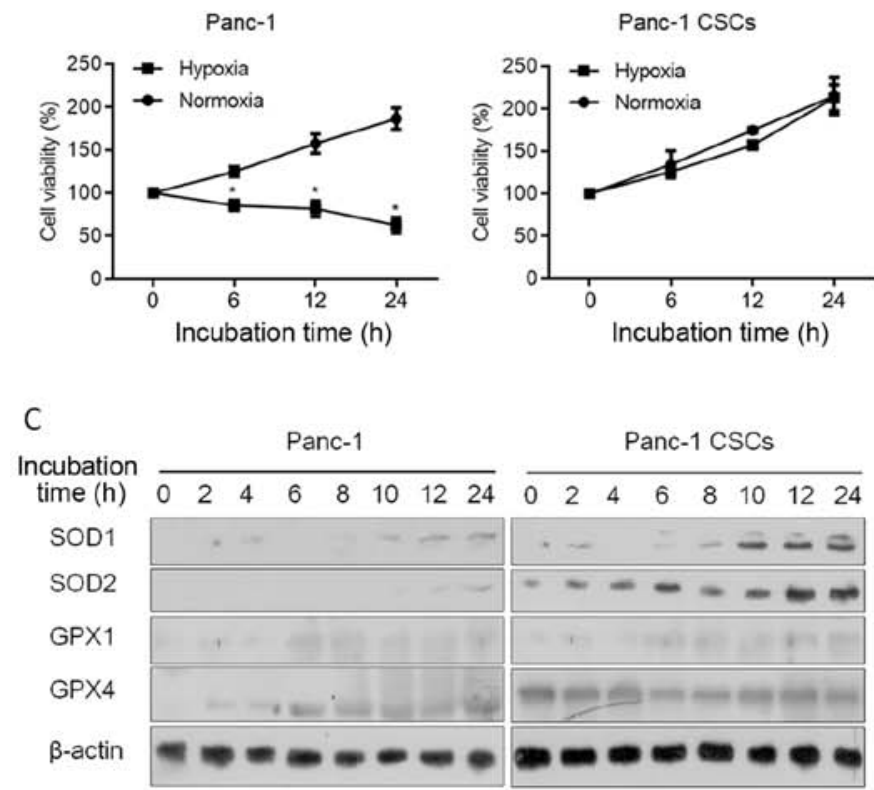

D
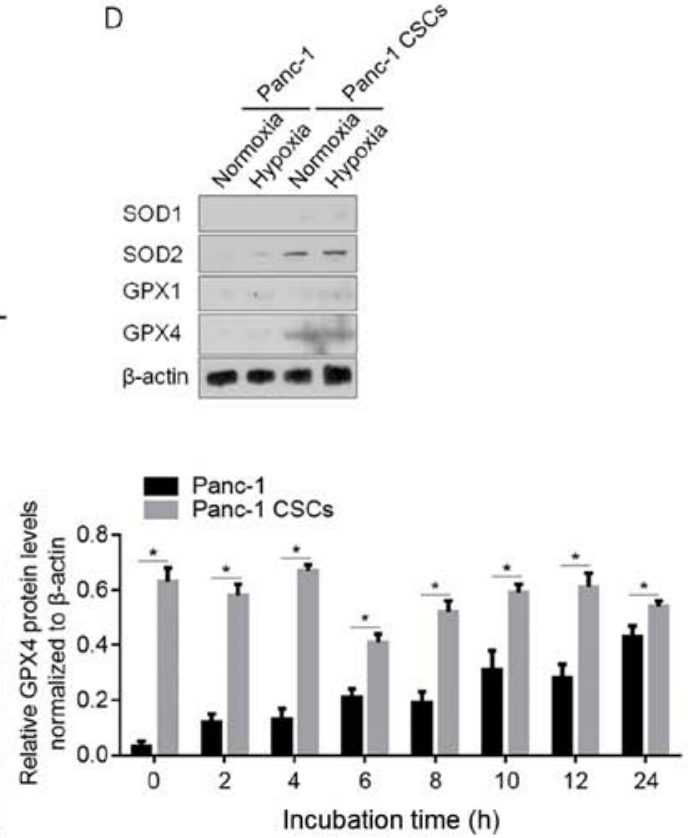

Figure 2. Hypoxia induced upregulation of SOD1, SOD2, GPX1 and GPX4 in both Panc-1 and Panc-1 CSCs. (A) The apoptotic cell death was detected under normoxia or hypoxia condition in Panc-1 and Panc-1 CSCs. (B) Cell viability assay was performed by CCK-8 staining for evaluating the effects of hypoxia on Panc-1 or Panc-1 CSCs. "P<0.05 vs. normoxia-treated cells. (C) Protein levels of SOD1, SOD2, GPX1 and GPX4 were detected by western blot analysis in Panc-1 or Panc-1 CSCs after hypoxia exposure. "P<0.05 vs. Panc-1 cells. (D) Western blot analysis was performed to detect the relative expression levels of SOD1, SOD2, GPX1 and GPX4 in Panc-1 and Panc-1 CSCs after hypoxia or normoxia exposure. CSCs, cancer stem-like cells; SOD, superoxide dismutase; GPX, glutathione peroxidase.

Panc-1 cells $(9.8 \pm 0.9 \%$ for $12 \mathrm{~h}$; $11.6 \pm 1.7 \%$ for $24 \mathrm{~h})$. Then the effects of hypoxia on cell viability were assessed. It was observed that, in Panc-1 CSCs, hypoxia exposure failed to decrease cell viability after $24 \mathrm{~h}$ (Fig. 2B). By considering the roles of SODs and GPXs in maintaining low intracellular ROS level in mammalian cells (34), western blot analysis was performed to detect the SOD and GPX protein levels in the Panc-1 and Panc-1 CSCs after hypoxic exposure. Expectedly, SOD1, SOD2 and GPX1 levels were induced by hypoxic exposure (Fig. 2C). However, GPX4 presented a relative high expression level in the Panc-1 CSCs compared with that in the Panc-1 cells, and GPX4 expressing levels were not obviously affected by hypoxic exposure in the Panc-1 CSCs. To confirm whether GPX4 presents a high endogenous level beyond hypoxic exposure, SODs and GPXs were compared in the Panc-1 and Panc-1 CSCs. In Fig. 2D, it was observed that, in the Panc-1 CSCs, GPX4 presented a consistently high endogenous level, which was obviously higher than that noted in the Panc-1 cells and did not respond to hypoxic exposure. This demonstrated that GPX4 potentially play critical roles in regulating physiological processes in panc-1 CSCs, not only after hypoxic exposure.

Endogenous GPX4 regulates oxidative homeostasis and exerts a protective effect on cell viability. For identifying the transfecting efficiency of siRNA by Lipofectamine ${ }^{\mathrm{TN}} 2000$, Alexa 
A
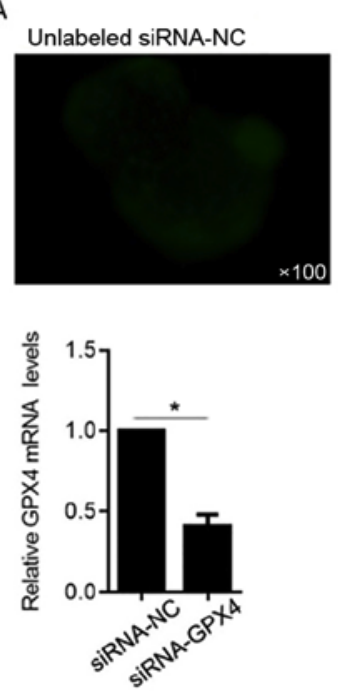

D

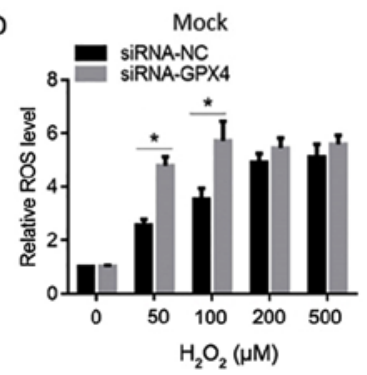

Alexa Fluor 488-labeled siRNA-NC
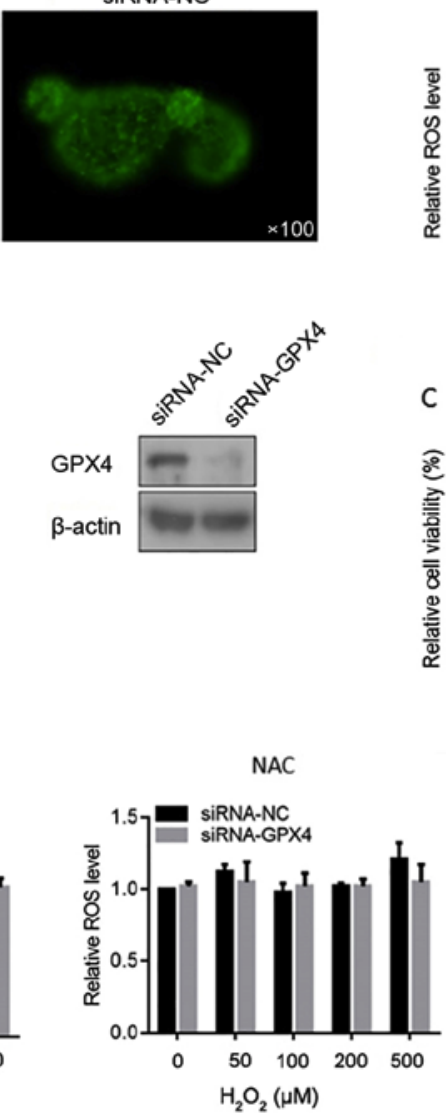

B

B Panc-1 CSCs

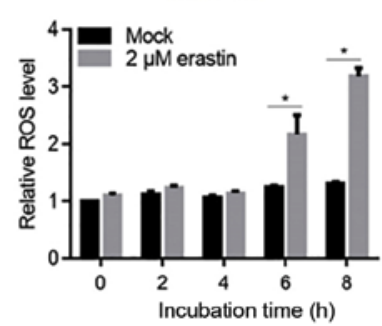

C

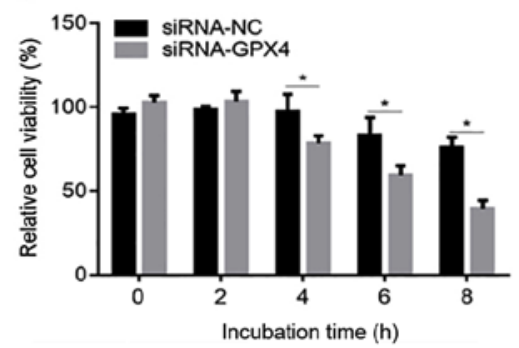

SiRNA-GPX4

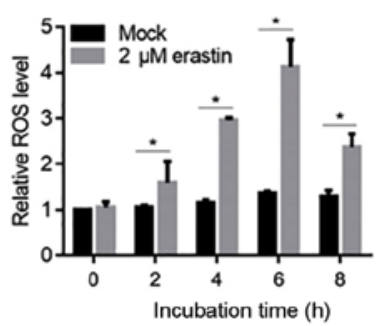

Figure 3. GPX4 exerts a regulatory role on maintaining homeostasis in Panc-1 CSCs. (A) siRNA targeted to GPX4 was introduced into Panc-1 CSCs by Lipofectamine ${ }^{\mathrm{TM}}$ transfection, and transfection efficiency was determined by observing the percentage of GFP-positive cells (upper panels). The knockdown efficiency was determined by measuring mRNA and protein levels of GPX4 by RT-qPCR and western blot analysis (lower panels). " $\mathrm{P}<0.05$ vs. siRNA-NC. (B) ROS accumulation was measured after erastin treatment after siRNA-GPX4 transfection. ${ }^{*} \mathrm{P}<0.05$ vs. mock group. (C) CCK-8 assay was performed to detect the cell viability with or without GPX4 knockdown after 12 -h hypoxia exposure. ${ }^{*} \mathrm{P}<0.05$ vs. siRNA-NC. (D) ROS accumulation was measured after different concentrations of $\mathrm{H}_{2} \mathrm{O}_{2}$ for $2 \mathrm{~h}$ in GPX4-knockdown Panc-1 CSCs without or with NAC pre-treatment (ROS scavenger). "P<0.05 vs. siRNA-NC. CSCs, cancer stem-like cells; GPX4, glutathione peroxidase 4; ROS, reactive oxygen species.

Fluor 488-labeled siRNA-NC was introduced into the Panc-1 CSCs and was detected immediately after 3 PBS washes. As shown in Fig. 3A (upper panels), siRNA-NC was successfully introduced into the Panc-1 CSCs. Then, the knockdown efficiency of the siRNA targeted to GPX4 mRNA (siRNA-GPX4) was measured by RT-qPCR and western blot analysis 2 days after transfection. The mRNA level of GPX4 was downregulated by $>50 \%$. In addition, a detectable downregulation in the protein level of GPX4 was also confirmed (Fig. 3A, lower panels).

By considering the inactivating ability of erastin to GPX enzymes, especially GPX4 (35), we examined the ROS accumulation of Panc-1 CSCs treated with targeted siRNA 3 days after transfection treated with $2 \mu \mathrm{M}$ erastin (Fig. 3B). Cells transfected with siRNA-GPX4 presented significant high ROS levels at 2- or 4-h of erastin treatment, while the control cells presented no detectable ROS accumulation. We then examined the effects of GPX4 knockdown on the cell growth of Panc-1 CSCs, which were exposed to hypoxia for $12 \mathrm{~h}$ previously, using CCK-8 assay. There was no significant difference in cell viability between cells transfected with GPX4 and control siRNA up to 0 and $2 \mathrm{~h}$ after erastin treatment (Fig. 3C). However, at $4 \mathrm{~h}$ after erastin treatment, the viability of the
siRNA-GPX4 transfected cells was significantly lower than that of the siRNA-NC transfected cells, suggesting that GPX4 exerts protective effect for cell viability against erastin treatment. We further clarify the ROS eliminating effect of GPX4 under oxidative stress condition induced by $\mathrm{H}_{2} \mathrm{O}_{2}$. As shown in Fig. 3D right panel, NAC pre-treatment scavenged ROS in cells. In Fig. 3D left panel, without NAC treatment (mock groups), GPX4 knockdown promoted the ROS accumulation at 50 and $100 \mu \mathrm{M}$ (Fig. 3D).

Knockdown of GPX4 tightly regulates physiological processes and inhibits the stemness phenotype in the Panc-1 CSCs. Previously, we showed that the presence of GPX4 exerted protective effects to Panc-1 CSCs under oxidative stresses including $\mathrm{H}_{2} \mathrm{O}_{2}$ or erastin (Fig. 3). To further investigate whether GPX4 plays certain roles without oxidative stress in Panc-1 CSCs, its effects on cell proliferation was determined. By performing CCK-8 assay and cell counting, it was observed that, without disturbing cell viability, GPX4 knockdown decreased cell proliferation compared to that of the siRNA-NC (Fig. 4A). Flow cytometric analysis after PI staining further showed that GPX4 knockdown arrested the cell cycle at the $\mathrm{G}_{1} / \mathrm{G}_{0}$ phase, indicating cell cycle arrest 

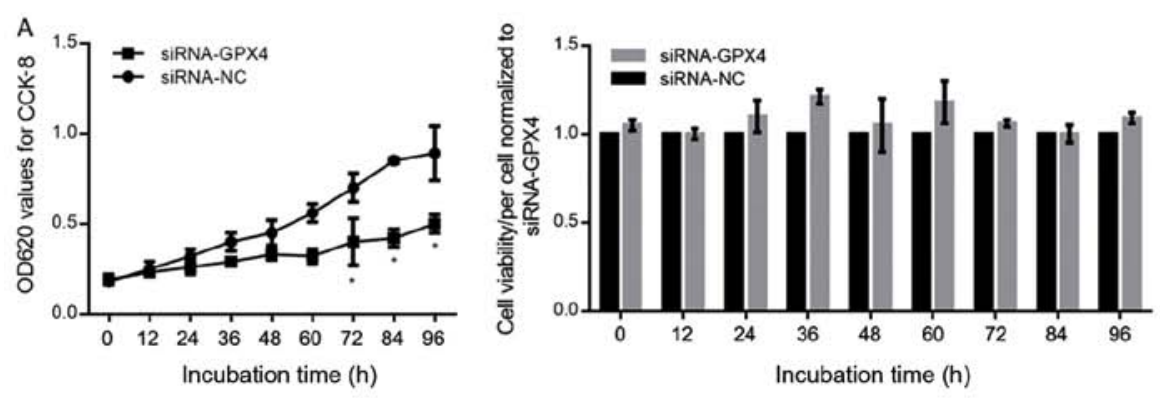

B
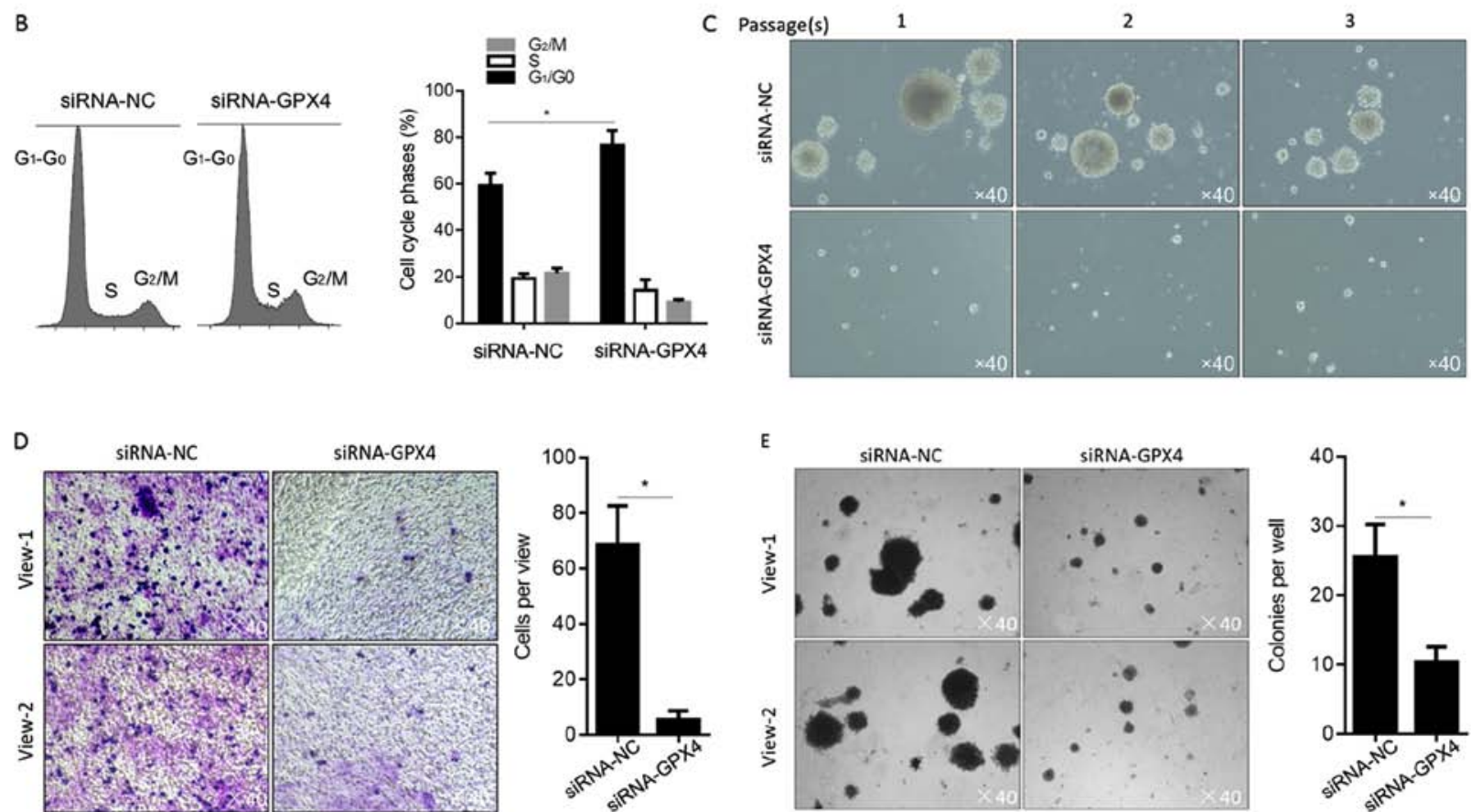

Figure 4. Knockdown of GPX4 decreases the stemness of Panc-1 CSCs and promotes apoptotic cell death. (A) CCK-8 assay was performed to detect the cell viability after siRNA-GPX4 introduction. "P<0.05 vs. siRNA-NC. (B) Flow cytometry after PI staining was performed to detect the cell phase distribution after siRNA-GPX4 introduction. "P<0.05 vs. siRNA-NC. (C) After transfection of siRNA-GPX4, the self-renewal capacity was measured by serial replating assay. (D) Transwell assay was performed to evaluate the effects of GPX4 on the migration ability of Panc-1 CSCs. "P<0.05 vs. siRNA-NC. (E) Colony formation was performed to detect the tumor formation on soft agar after siRNA-GPX4 introduction. "P<0.05 vs. siRNA-NC. CSCs, cancer stem-like cells; GPX4, glutathione peroxidase 4; PI, propidium iodide.

at this phase (Fig. 4B). The results of functional analysis showed that knockdown of GPX4 significantly suppressed sphere formation ability (Fig. 4C), migration and invasion capacity (Fig. 4D and E) in Panc-1 CSCs, as compared with siRNA-NC cells. Collectively, our results revealed that knockdown of GPX4 suppressed the stemness phenotype of Panc-1 CSCs and inhibited in vitro cell functions.

Overexpression of GPX4 suppressed the stemness phenotype and exerts protective effects under oxidative stress. We further evaluated the effects of the overexpression of GPX4 on stemness characteristics and chemosensitivity in Panc-1 CSCs. After stable transfection of GPX4, its mRNA and protein levels were obviously overexpressed (Fig. 5A). Expectedly, after oxidative stress exposure, overexpression of GPX4 inhibited the accumulation of ROS after $\mathrm{H}_{2} \mathrm{O}_{2}$ or erastin treatment (Fig. 5B). By performing serial-replating assay with the existence of $100 \mu \mathrm{M} \mathrm{H}_{2} \mathrm{O}_{2}$, it was found that overexpression of GPX4 promoted sphere formation at passage 3 and 4, indicating that the self-renewal capacity of the Panc-1 CSCs was promoted by overexpression of GPX4 (Fig. 5C). Followed by detection of physiological processes under oxidative stress $\left(100 \mu \mathrm{M} \mathrm{H}_{2} \mathrm{O}_{2}\right)$, it was revealed that overexpression of GPX4 promoted cell proliferation (Fig. 5D), migration (Fig. 5E) and invasion (Fig. 5F). In order to ascertain whether overexpression of GPX4 inhibits oxidative stress-induced cell death in Panc-1 CSCs, the cells pretreated with apoptotic death inhibitor (Z-VAD-FMK), ferroptotic death inhibitor (Ferr-1) or necrotic death inhibitor (Nec-1) were treated with oxidative stress $\left(100 \mu \mathrm{M} \mathrm{H}_{2} \mathrm{O}_{2}\right.$ or $2 \mu \mathrm{M}$ erastin) and stained using CFSE/PI followed by flow cytometric analysis. As shown in Fig. 5G, overexpression of GPX4 inhibited apoptotic cell death induced by $\mathrm{H}_{2} \mathrm{O}_{2}$, ferroptotic and necrotic cell death induced by erastin. All these data showed that overexpression of GPX4 exerts protective effects under oxidative stress.

GPX4 plays a critical role in the partial regulation of the EMT phenotype in Panc-1 CSCs. ROS level is reported to be directly and tightly related to EMT-programme activation (35). This promoted us to ascertain whether $\mathrm{H}_{2} \mathrm{O}_{2}$ or erastin-induced 


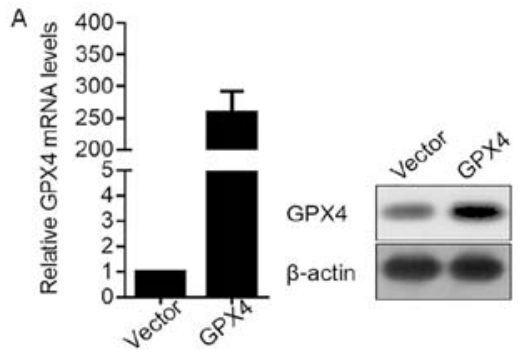

B
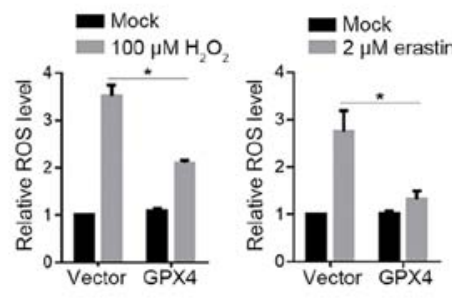

E Vector
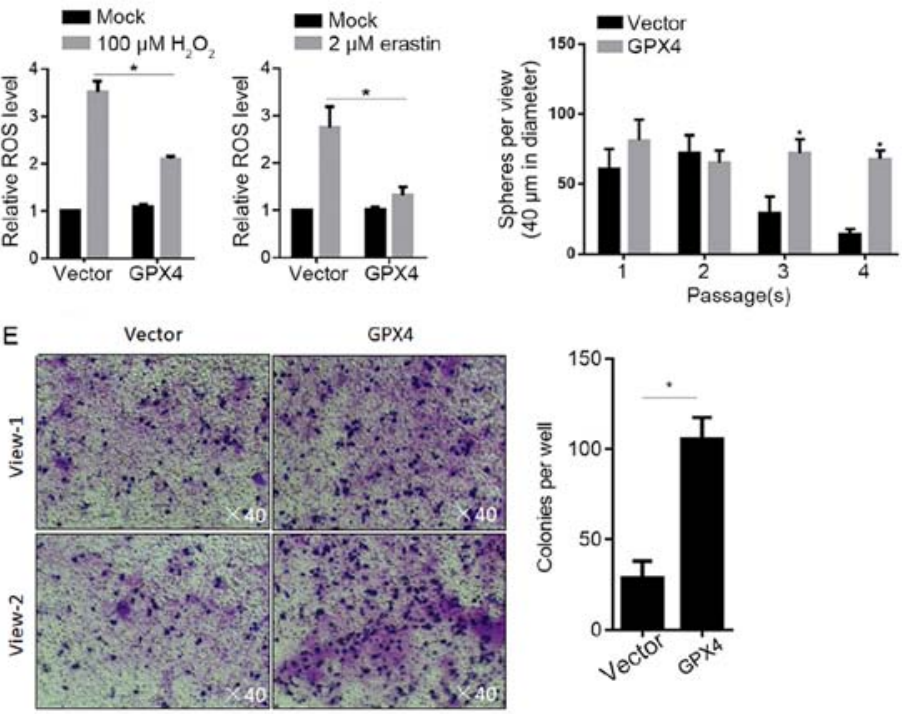

D

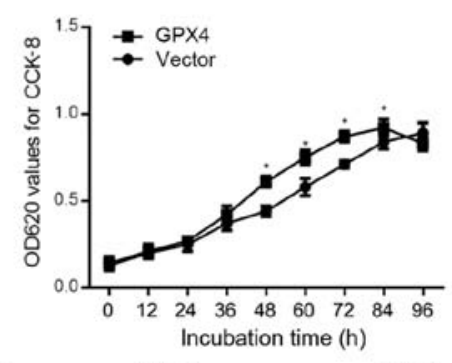

F

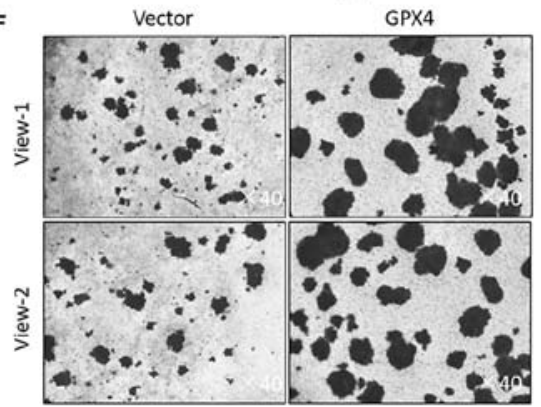

G

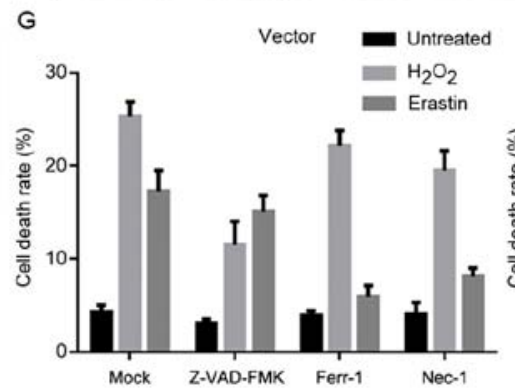

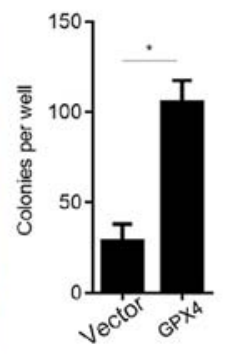

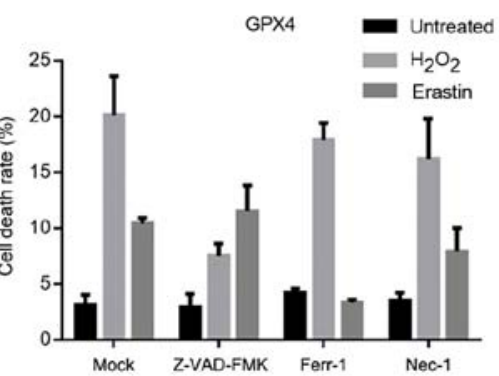

Figure 5. Overexpression of GPX4 impairs the stemness of Panc-1 CSCs in a normal condition and exerts protective effects on Panc-1 CSCs in ROS-inducing condition. (A) Overexpression of GPX4 was detected by RT-qPCR and western blot analysis. (B) After overexpression of GPX4 in Panc-1 CSCs, ROS generation after $\mathrm{H}_{2} \mathrm{O}_{2}$ or erastin treatment was measured. ${ }^{*} \mathrm{P}<0.05$ vs. Mock group transfected with vector. (C) Serial replating assay was performed to evaluate the effects of the upregulation of GPX4 on the stemness of Panc-1 CSCs. Upregulation of GPX4 promoted cell proliferation, colony formation and invasion as confirmed by (D) CCK-8 assay, (E) Transwell assay and (F) soft agar colony formation. ${ }^{*} \mathrm{P}<0.05$ vs. vector-transfected cells. (G) After being pretreated with Z-VAD-FMK, Ferr-1 or Nec-1, the cell death rate caused by $\mathrm{H}_{2} \mathrm{O}_{2}$ or erastin treatment was measured by CFSE/PI double staining. CSCs, cancer stem-like cells; GPX4, glutathione peroxidase 4; ROS, reactive oxygen species.
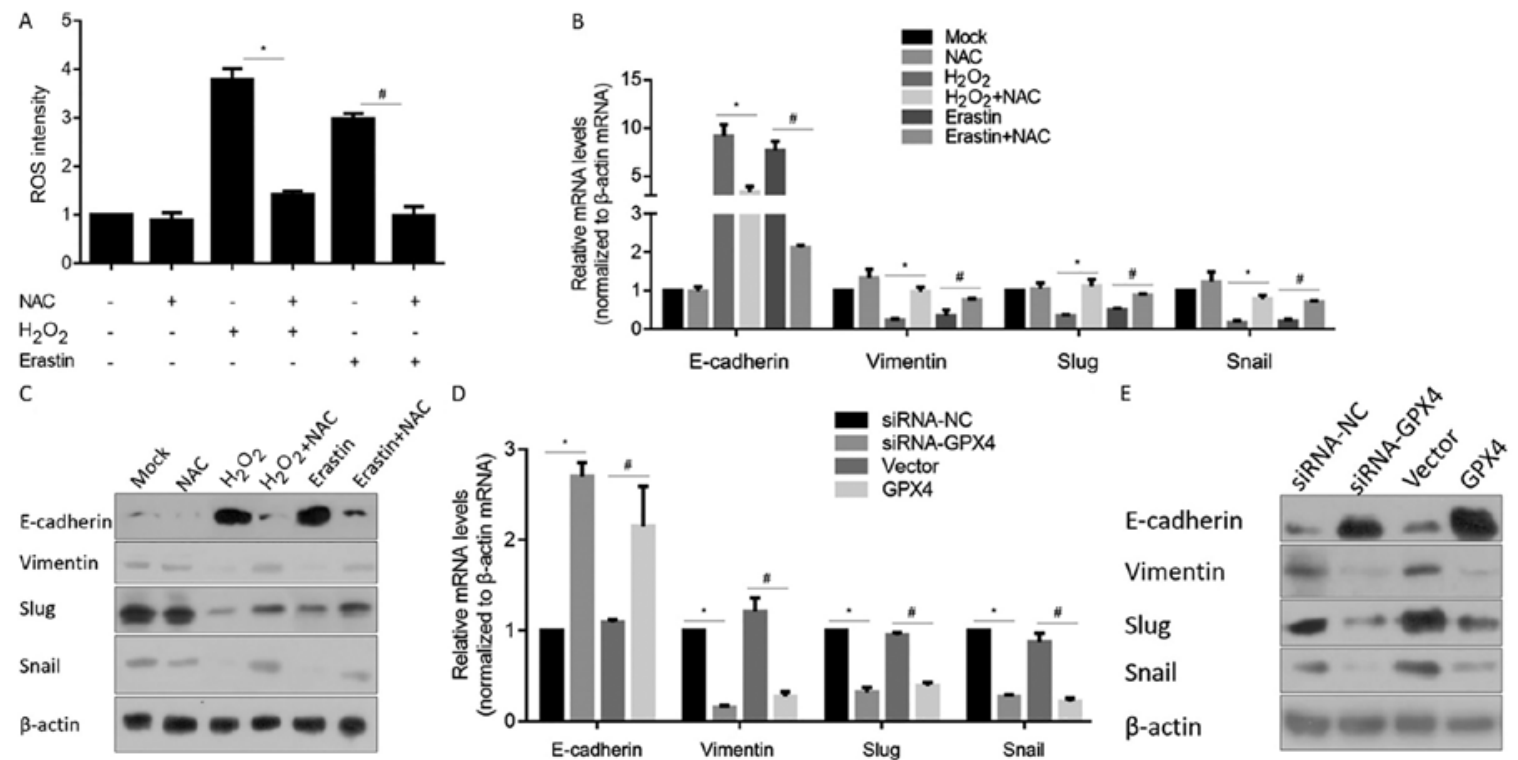

Figure 6. GPX4 plays a partial role in maintaining the EMT phenotype. (A) ROS levels were measured after $\mathrm{H}_{2} \mathrm{O}_{2}$ or erastin treatment in Panc-1 CSCs. "P $<0.05$ vs. $\mathrm{H}_{2} \mathrm{O}_{2}$-treated cells; ${ }^{*} \mathrm{P}<0.05$ vs. erastin-treated cells. (B) RT-qPCR and (C) western blot analysis were performed to detect the mRNA and protein levels of E-cadherin, vimentin, Slug and Snail. " $\mathrm{P}<0.05$ vs. $\mathrm{H}_{2} \mathrm{O}_{2}$-treated cells; ${ }^{*} \mathrm{P}<0.05$ vs. erastin-treated cells. (D) RT-qPCR and (E) western blot analysis were performed to detect the mRNA and protein levels of E-cadherin, vimentin, Slug and Snail in siRNA-NC, siRNA-GPX4, vector- or GPX4-transfected Panc-1 CSCs. " $\mathrm{P}<0.05$ vs. siRNA-NC; ${ }^{*} \mathrm{P}<0.05$ vs. vector-transfected cells. CSCs, cancer stem-like cells; GPX4, glutathione peroxidase 4; EMT, epithelial-to-mesenchymal transition; ROS, reactive oxygen species. 
ROS accumulation regulates EMT-programme processes. Firstly, we tested the ROS eliminating effect of $\mathrm{N}$-acetyl cysteine (NAC), a ROS scavenger, after $\mathrm{H}_{2} \mathrm{O}_{2}$ or erastin induction. As expected, NAC efficiently eliminated ROS after oxidative stress (Fig. 6A), thus, in further experiments, NAC was employed as a ROS scavenger. RT-qPCR results for detection of mRNA levels of EMT hallmark genes, including E-cadherin, vimentin, Slug and Snail showed that both $\mathrm{H}_{2} \mathrm{O}_{2}$ and erastin treatment upregulated E-cadherin and downregulated vimentin, Slug and Snail mRNA levels (Fig. 6B), while elimination of ROS by a scavenger inhibited these changes, indicating that the generated ROS are attributed to the regulation of EMT. Consistently, protein levels of E-cadherin, vimentin, Slug and Snail were consistent with the tendency of mRNA levels (Fig. 6C).

By considering that the difference between CSCs and non-CSCs is likely to be attributable largely to the cell biological programme termed EMT $(37,38)$, the effects of modified GPX4 on EMT hallmark genes were further detected by RT-qPCR and western blot analysis. Both knockdown and overexpression of GPX4 upregulated E-cadherin, downregulated vimentin, Slug and Snail at the mRNA and protein levels, indicating its inhibitory effect on the EMT programme (Fig. 6D and E), which is consistent with the morphologic changes.

\section{Discussion}

ROS are recognized as critical cellular signalling molecules. The maintenance of ROS is critical for a wide array of biological processes, including cell viability, proliferation, apoptosis and angiogenesis (1). In tumours, emerging evidence suggests that accumulation of ROS is associated with the generation of CSCs and the activation of the EMT programme upon hypoxia exposure, and it is considered the most common characteristic associated with tumourigenesis and tumour progression (39). The antioxidant system is intensively studied in mammalian cells (40), however, the importance of a specific antioxidant enzyme has not been fully understood in Panc-1 CSCs. In the present study, we enriched CSCs from Panc-1 cells using serum-free medium. After comparison of several major antioxidant enzymes, including SOD1, SOD2, GPX1 and GPX4 after hypoxic exposure, we found that SOD1, SOD2 and GPX1 were upregulated in both Panc-1 and Panc-1 CSCs. Surprisingly, GPX4 displayed a much higher level of expression in Panc-1 CSCs compared with Panc-1 cells under normoxic conditions. This suggests the importance of GPX4 as a potential key regulator of oxidative homeostasis under normoxic conditions in Panc-1 CSCs. Knockdown and overexpression studies of GPX4 were employed to discern the importance of GPX4 in maintaining oxidative homeostasis in Panc-1 CSCs. According to our results, both overexpression and knockdown of GPX4 increased epithelial markers and decreased mesenchymal ones, and eliminated the characteristics of Panc-1 CSCs without oxidative stress, suggesting that GPX4 may be critical for maintaining oxidative homeostasis. In our hypothesis, both upregulation and downregulation of GPX4 inactivate the EMT programme in unknown mechanisms, which requires further investigation.
Both SODs and GPXs are critical scavenger antioxidative enzyme systems, which are responsible for eliminating accumulated intracellular ROS induced by hypoxia or oxidant exposure. Formed ROS are converted by SODs to $\mathrm{H}_{2} \mathrm{O}_{2}$ and subsequently converted by GPXs to $\mathrm{H}_{2} \mathrm{O}+\mathrm{O}_{2}$ (3). In both Panc-1 and Panc-1 CSCs, hypoxia exposure stimulated the expression of SOD1, SOD2 and GPX1, which is consistent with a previous report (4). To avoid the involvement of SODs in ROS elimination, cells were treated with $\mathrm{H}_{2} \mathrm{O}_{2}$ to generate ROS in Panc-1 CSCs. As expected, without the involvement of SODs, GPX4 exerted a critical role in eliminating ROS in CSCs (41). After hypoxic exposure, both SODs and GPXs were upregulated in Panc-1 CSCs, which is consistent with a previous report (42). Notably, before hypoxia stimulation, endogenous GPX4 was relatively high in CSCs and there was no obvious upregulation after hypoxic exposure, suggesting a role for GPX4 under normal conditions. Erastin induces ROS accumulation and ferroptotic cell death (43). We showed that expression of GPX4 exerted antioxidant effects in response to erastin-induced oxidant injury, suggesting that GPX4 exerts protective effects mainly via eliminating ROS induced in a different manner.

EMT has been reported as an important regulator of cancer cells exhibiting stem cell-like properties (44), and EMT is closely linked to a stem cell phenotype in CSCs. In the present study, we demonstrated that changes in GPX4 expression led to decreases in the EMT phenotype and reduction in the stemness phenotype in Panc-1 CSCs. These results indicate that GPX4 potentially regulates the stemness phenotype via regulation of ROS accumulation and the EMT programme. There is still a limitation of this study that only a single cell line was used. For generalizing the results obtained, we intend to test the roles of GPX4 in another cellular system in vitro and in other cancer stem-like cells derived from other organs, and to confirm the roles of GPX4 in human pancreatic tumor tissues in further studies.

Collectively, we demonstrated that GPX4 is upregulated in Panc-1 CSCs compared with parental Panc-1 cells. The elevated levels of GPX4 are responsible for regulating oxidative homeostasis, maintaining the EMT programme and maintaining the CSC phenotype. These data suggest that GPX4 is a possible therapeutic target to prevent the development of resistance to oxidative stress.

\section{Acknowledgements}

We would like to thank Professor Hummin Zhao (Sichuan University) for the language editing.

\section{Funding}

The present study was funded by the Traditional Chinese Medicine Scientific Support program of Health and Family Planning Commision of Chongqing (no. ZY201703017).

\section{Availability of data and materials}

The datasets used and/or analyzed during the current study are available from the corresponding author on reasonable request. 


\section{Authors' contributions}

GP designed part of the experiments and performed the gene expressing and the cell culture relative experiments. ZT and YX performed the gene expression analysis and some cell culture relative experiments. YX wrote the draft of the manuscript. WC designed part of the experiments and supervised the whole procedure. All authors read and approved the manuscript and agree to be accountable for all aspects of the research in ensuring that the accuracy or integrity of any part of the work are appropriately investigated and resolved.

\section{Ethics approval and consent to participate}

Not applicable.

\section{Patient consent for publication}

Not applicable.

\section{Competing interests}

The authors declare that they have no competing interests.

\section{References}

1. Bao B, Azmi AS, Li Y, Ahmad A, Ali S, Banerjee S, Kong D and Sarkar FH: Targeting CSCs in tumor microenvironment: The potential role of ROS-associated miRNAs in tumor aggressiveness. Curr Stem Cell Res Ther 9: 22-35, 2014.

2. Klaunig JE, Kamendulis LM and Hocevar BA: Oxidative stress and oxidative damage in carcinogenesis. Toxicol Pathol 38: 96-109, 2010.

3. Trachootham D, Alexandre J and Huang P: Targeting cancer cells by ROS-mediated mechanisms: A radical therapeutic approach? Nat Rev Drug Discov 8: 579-591, 2009.

4. Jiao Y, Wang Y, Guo S and Wang G: Glutathione peroxidases as oncotargets. Oncotarget 8: 80093-80102, 2017.

5. Cejas P, García-Cabezas MA, Casado E, Belda-Iniesta C, De Castro J, Fresno JA, Barriuso J, Espinosa E, Zamora P, Feliu J, et al: Phospholipid hydroperoxide glutathione peroxidase (PHGPx) expression is downregulated in poorly differentiated breast invasive ductal carcinoma. Free Radic Res 41: 681-687, 2007.

6. Al-Taie OH, Uceyler N, Eubner U, Jakob F, Mörk H, Scheurlen M, Brigelius-Flohe R, Schöttker K, Abel J, Thalheimer A, et al: Expression profiling and genetic alterations of the selenoproteins GI-GPx and SePP in colorectal carcinogenesis. Nutr Cancer 48: 6-14, 2004.

7. Falck E, Karlsson S, Carlsson J, Helenius G, Karlsson M and Klinga-Levan $\mathrm{K}$ : Loss of glutathione peroxidase 3 expression is correlated with epigenetic mechanisms in endometrial adenocarcinoma. Cancer Cell Int 10: 46, 2010.

8. Liu J, Du J, Zhang Y, Sun W, Smith BJ, Oberley LW and Cullen JJ: Suppression of the malignant phenotype in pancreatic cancer by overexpression of phospholipid hydroperoxide glutathione peroxidase. Hum Gene Ther 17: 105-116, 2006.

9. Yu YP, Yu G, Tseng G, Cieply K, Nelson J, Defrances M, Zarnegar R, Michalopoulos $\mathrm{G}$ and Luo JH: Glutathione peroxidase 3 , deleted or methylated in prostate cancer, suppresses prostate cancer growth and metastasis. Cancer Res 67: 8043-8050, 2007.

10. Bonnet D and Dick JE: Human acute myeloid leukemia is organized as a hierarchy that originates from a primitive hematopoietic cell. Nat Med 3: 730-737, 1997.

11. Kensler TW, Wakabayashi $\mathrm{N}$ and Biswal S: Cell survival responses to environmental stresses via the Keap1-Nrf2-ARE pathway. Annu Rev Pharmacol Toxicol 47: 89-116, 2007.

12. Ito K, Hirao A, Arai F, Takubo K, Matsuoka S, Miyamoto K, Ohmura M, Naka K, Hosokawa K, Ikeda Y, et al: Reactive oxygen species act through p38 MAPK to limit the lifespan of hematopoietic stem cells. Nat Med 12: 446-451, 2006.
13. Bell EL, Klimova TA, Eisenbart J, Moraes CT, Murphy MP, Budinger GR and Chandel NS: The $\mathrm{Q}_{\mathrm{o}}$ site of the mitochondrial complex III is required for the transduction of hypoxic signaling via reactive oxygen species production. J Cell Biol 177: 1029-1036, 2007.

14. Huang J, Yang J, Maity B, Mayuzumi D and Fisher RA: Regulator of $\mathrm{G}$ protein signaling 6 mediates doxorubicin-induced ATM and p53 activation by a reactive oxygen species-dependent mechanism. Cancer Res 71: 6310-6319, 2011.

15. Juntilla MM, Patil VD, Calamito M, Joshi RP, Birnbaum MJ and Koretzky GA: AKT1 and AKT2 maintain hematopoietic stem cell function by regulating reactive oxygen species. Blood 115: 4030-4038, 2010.

16. Diehn M, Cho RW, Lobo NA, Kalisky T, Dorie MJ, Kulp AN, Qian D, Lam JS, Ailles LE, Wong M, et al: Association of reactive oxygen species levels and radioresistance in cancer stem cells. Nature 458: 780-783, 2009.

17. Ye XQ, Li Q, Wang GH, Sun FF, Huang GJ, Bian XW, Yu SC and Qian GS: Mitochondrial and energy metabolism-related properties as novel indicators of lung cancer stem cells. Int J Cancer 129: 820-831, 2011.

18. Kim HM, Haraguchi N, Ishii H, Ohkuma M, Okano M, Mimori K, Eguchi H, Yamamoto H, Nagano H, Sekimoto M, et al: Increased CD13 expression reduces reactive oxygen species, promoting survival of liver cancer stem cells via an epithelial-mesenchymal transition-like phenomenon. Ann Surg Oncol 19 (Suppl 3): S539-S548, 2012.

19. Thompson EW, Newgreen DF and Tarin D: Carcinoma invasion and metastasis: A role for epithelial-mesenchymal transition? Cancer Res 65: 5991-5995, 2005.

20. Mani SA, Guo W, Liao MJ, Eaton EN, Ayyanan A, Zhou AY, Brooks M, Reinhard F, Zhang CC, Shipitsin M, et al: The epithelial-mesenchymal transition generates cells with properties of stem cells. Cell 133: 704-715, 2008.

21. Morel AP, Lièvre M, Thomas C, Hinkal G, Ansieau S and Puisieux A: Generation of breast cancer stem cells through epithelial-mesenchymal transition. PLoS One 3: e2888, 2008.

22. Chi HC, Tsai CY, Tsai MM, Yeh CT and Lin KH: Roles of long noncoding RNAs in recurrence and metastasis of radiotherapy-resistant cancer. Int J Mol Sci 18: pii: E1903, 2017.

23. Cannito S, Novo E, di Bonzo LV, Busletta C, Colombatto S and Parola M: Epithelial-mesenchymal transition: From molecular mechanisms, redox regulation to implications in human health and disease. Antioxid Redox Signal 12: 1383-1430, 2010.

24. Giannoni E, Parri M and Chiarugi P: EMT and oxidative stress: A bidirectional interplay affecting tumor malignancy. Antioxid Redox Signal 16: 1248-1263, 2012.

25. Bao B, Azmi AS, Ali S, Ahmad A, Li Y, Banerjee S, Kong D and Sarkar FH: The biological kinship of hypoxia with CSC and EMT and their relationship with deregulated expression of miRNAs and tumor aggressiveness. Biochim Biophys Acta 1826: 272-296, 2012.

26. Fu Z, Li G, Li Z, Wang Y, Zhao Y, Zheng S, Ye H, Luo Y, Zhao X, Wei L, et al: Endogenous miRNA sponge lincRNA-ROR promotes proliferation, invasion and stem cell-like phenytype of pancreatic cancer cells. Cell Death Discov 3: 17004, 2017.

27. Livak KJ and Schmittgen TD: Analysis of relative gene expression data using real-time quantitative PCR and the 2- $\Delta \Delta C \mathrm{~T}$ method. Methods 25: 402-408, 2001

28. Clarke MF, Dick JE, Dirks PB, Eaves CJ, Jamieson CH, Jones DL, Visvader J, Weissman IL and Wahl GM: Cancer stem cells-perspectives on current status and future directions: AACR workshop on cancer stem cells. Cancer Res 66: 9339-9344, 2006.

29. Pradal R, Clarke MF and Morrison SJ: Applying the principle of stem-cell biology to cancer. Nat Rev Cancer 3: 895-902, 2003.

30. Ponti D, Costa A, Zaffaroni N, Pratesi G, Petrangolini G, Coradini D, Pilotti S, Pierotti MA and Daidone MG: Isolation and in vitro propagation of tumorigenic breast cancer cells with stem/progenitor cell properties. Cancer Res 65: 5506-5511, 2005.

31. Somervaille TC and Cleary ML: Identification and characterization of leukemia stem cells in murine MLL-AF9 acute myeloid leukemia. Cancer Cell 10: 257-268, 2006.

32. Sharma N, Nanta R, Sharma J, Gunewardena S, Singh KP, Shankar S and Srivastava RK: PI3K/AKT/mTOR and sonic hedgehog pathways cooperate together to inhibit human pancreatic cancer stem cell characteristics and tumor growth. Oncotarget 6: 32039-32060, 2015.

33. Yeung TM, Gandhi SC, Wilding JL, Muschel R and Bodmer WF: Cancer stem cells from colorectal cancer-derived cell lines. Proc Natl Acad Sci USA 107: 3722-3727, 2010. 
34. Galadari S, Rahman A, Pallichankandy S and Thayyullathil F: Reactive oxygen species and cancer paradox: To promote or to suppress? Free Radic Biol Med 104: 144-164, 2017.

35. Yang WS, SriRamaratnam R, Welsch ME, Shimada K, Skouta R, Viswanathan VS, Cheah JH, Clemons PA, Shamji AF Clish CB, et al: Regulation of ferroptotic cancer cell death by GPX4. Cell 156: 317-331, 2014.

36. Shibue T and Weinberg RA: EMT, CSCs, and drug resistance: The mechanistic link and clinical implications. Nat Rev Clin Oncol 14: 611-629, 2017.

37. Medema JP: Cancer stem cells: The challenges ahead. Nat Cell Biol 15: 338-344, 2013.

38. Polyak K and Weinberg RA: Transitions between epithelial and mesenchymal states: Acquisition of malignant and stem cell traits. Nat Rev Cancer 9: 265-273, 2009.

39. Ischenko I, Seeliger H, Kleespies A, Angele MK, Eichhorn ME, Jauch KW and Bruns CJ: Pancreatic cancer stem cells: New understanding of tumorigenesis, clinical implications. Langenbecks Arch Surg 395: 1-10, 2010.
40. Hayashi R, Himori N, Taguchi K, Ishikawa Y, Uesugi K, Ito M, Duncan T, Tsujikawa M, Nakazawa T, Yamamoto M, et al: The role of the Nrf2-mediated defense system in corneal epithelial wound healing. Free Radic Biol Med 61: 333-342, 2013.

41. Lu L, Oveson BC, Jo YJ, Lauer TW, Usui S, Komeima K, Xie B and Campochiaro PA: Increased expression of glutathione peroxidase 4 strongly protects retina from oxidative damage. Antioxid Redox Signal 11: 715-724, 2009.

42. Perrella MA and Yet SF: Role of heme oxygenase-1 in cardiovascular function. Curr Pharm Des 9: 2479-2487, 2003.

43. Maldonado EN, Sheldon KL, DeHart DN, Patnaik J, Manevich Y, Townsend DM, Bezrukov SM, Rostovtseva TK and Lemasters JJ: Voltage-dependent anion channels modulate mitochondrial metabolism in cancer cells: Regulation by free tubulin and erastin. J Biol Chem 288: 11920-11929, 2013.

44. Scheel C and Weinberg RA: Phenotypic plasticity and epithelial-mesenchymal transitions in cancer and normal stem cells? Int J Cancer 129: 2310-2314, 2011. 